\title{
The relationship between performance under stress and blood biochemistry in monkeys ${ }^{1,2}$
}

\author{
W. F. ANGERMEIER AND J. B. PHELPS, FLORIDA PRESBYTERIAN COLLEGE \\ H. H. REYNOLDS, ARL HOLLOMAN AFB. NEW MEXICO
}

Twenty-four male rhe sus monkeys were subjected to extensive discrimination training under stress. Biochemical values of the blood, such as Glutamic Oxalacetic Transaminase, Cholinesterase, Tyrosine, Cholesterol, Serum Total Protein, White Blood Count, Albumin, Beta Globulin, and certain Leukocytes seemed to vary virtually point for point with the temporal adaptation to the tasks presented to the animals. The find ings were interpreted to indicate that the se biochemical measures reflect the degree of performance stress to which the experimental Ss were exposed.

A number of investigators have described the effects of exposure to stressful conditions upon various biochemical factors (Selye, 1950; Henry, 1964; Wegman, Bruener, Klein, \& Voigt, 1966; Pearl, Balazs, \& Buyske, 1966; Naumov, 1964; Alan, Boctor, Rogers, \& Harper, 1965; Sarai, 1966; Dreyfuss \& Czaczkes, 1959; Geber, Anderson, \& Van Dyne, 1966). Most of these studies, however, were limited by one or more of the following three factors: (1) Only specific physical or chemical stressors were applied to the experimental Ss; (2) The number of different biochemical assessments was limited; and (3) The biochemical variations in time have largely been neglected. A notable exception to the latter criticism is the work of Selye (1950).

The study reported here attempted to determine the relationship between performance under stress over a period of time and a series of 21 biochemical measures derived from the blood of 16-18 month old male rhesus monkeys.

\section{Subjects}

Twenty-four male rhesus monkeys (Macaca mulatta), 16 to 18 months old, were used as Ss. The animals had been reared under four different conditions of social and perceptual deprivation and enrichment. Details of these procedures are described elsewhere (Angermeier \& Phelps, 1967). The animals were provided fresh fruit and a balanced biscuit diet twice daily. Animals used in the positive reinforcement task were reduced to 90 percent of their normal body weights and maintained at that level for the duration of the experiment.

\section{Apparatus}

The test apparatus is described in detail elsewhere (Angermeier \& Phelps, 1967). Briefly, the apparatus provided for a match-to-sample response with the aid of inline digital display units (IDDs), mounted behind clear plastic response buttons. The Ss assigned to the positive reinforcement task received a $0.3-\mathrm{g}$ banana pellet for matching a stimulus sample correctly. Reinforcement for the negative animals consisted of aroidance of a mild electric shock. The avoldance response had to occur within $3 \mathrm{sec}$ of the stimulus sample presentation. The matching response for both groups was based upon brightness discrimination of two-dimensional geometric symbols $(\square, \Delta$, $O$, and + projected from the rear onto the response buttons. This task was made progressively more difficult through a series of 10 phases.

\section{Behavioral Procedure}

Half of the animals were assigned to the positively and half to the negatively reinforced task. After appropriate approach training, the animals were given 50 trials daily for a period of three months, excepting weekends.

\section{Biochemical Procedure}

Ten cc of blood was drawn from the left or right great saphenous vein of all monkeys. The blood samples were taken during the first, third, and tenth week of behavioral testing. Adhering to standard method and procedures (for details see Angermeier \& Phelps, 1967) the following biochemical analyses were performed: Hematocrit, white blood count, leukocyte differentials, glucose, calcium, serum total protein, protein fractions, tyrosine, cholesterol, cholinesterase, and glutamic oxalacetic transaminase (SGOT). Results

The raw data were analyzed by a Type III analysis of variance (Lindquist, 1953). No differences obtained between the animals assigned to the positively and those assigned to the negatively reinforced discrimination task on any of the biochemical measures. The blood samples by groups interaction in the measure of Tyrosine showed statistical significance at the .025 level. A significant difference between groups was apparent in the measure of Calcium $(p<.05)$. Significant differences due to the temporal separation of the blood samples were found in the following measures: SGOT $(p<.025)$; Cholinesterase $(p<.001)$; Tyrosine ( $p<.001)$; Cholesterol $(p<.001)$; Serum Total Protein ( $p<.005)$; White Blood Count $(p<.01)$; Calcium $(p<.001)$; Albumin ( $<$.05); Beta Globulin ( $<<.005)$; Segmented Neutrophils $(p<.01)$; Lymphocytes $(p<.01)$; Monocytes $(p<.01)$; and Basophils $(p<.05)$. The reliability of temporal changes was tested by using the raw data and subjecting these to Kendall's coefficient of concordance (Siegel, 1956). Significant coefficients were obtained for Cholinesterase $(p<.01)$; Cholesterol $(p<.01)$; SGOT $(p<.05)$; Serum Total 


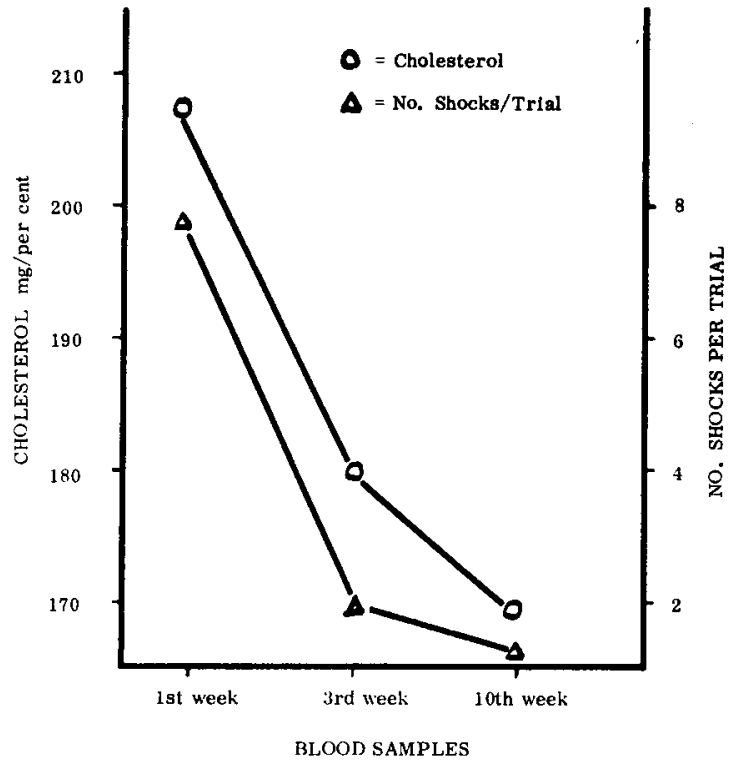

Fig. 1. Relationships between task performance and levels of cholesterol. Each point represents the mean of 24 Ss.

Protein ( $p<.01)$; Eosinophils ( $p<.05)$; Lymphocytes ( $p<.05)$; Segmented Neutrophils $(p<.05)$; Tyrosine $(p<.01)$; and Calcium ( $p<.01)$. Kendall's coefficient of concordance was also applied to the number of shocks which the animals received on the days of blood withdrawal (for the negatively reinforced Ss) and to the number of phases completed on the days of blood withdrawal (for the positively reinforced Ss). In both instances, the degree of concordance exceeded the .01 level ( $W=.81$ and .75 , respectively). Discussion

The data suggest that primate Ss undergoing discrimination learning are under considerable stress during the initial phases of adaptation to the learning task. The biochemical values seem to follow a course which closely parallels the reduction in errors (or number of shocks received) made by the animals during the behavioral phase. Figure 1 illustrates this fact. As the Ss mastered the task over a 10-week period, the biochemical values approached normal levels (Petery, 1965). An incidental observation was that virtually all of the biochemical values of the rhesus monkey closely approximate the values of the human S. This may prove to be an important consideration in view of the prevailing restrictions on long-range stress studies involving human Ss.

\section{References}

Alan, S. Q., Boctor, A. M., Rogers, Q. R., \& Harper, A. E. Effect of different amino acids, Celine and hydrocortisone on tyrosine toxicity. Fed. Proc., 1965, 24, 317.

Angermeier, W. F., \& Phelps, J. B. The effects of differential early experience upon learning, performance, and biochemical responses of nonhuman primates (rhesus monkeys). 6571 st Aeromed. Res. Lab. Tech. Rep., No. ARL-TR-67-10, Holloman Air Force Base, New Mexico, 1967, V, 1-64.

Dreyfuss, F., \& Czaczkes, J. W. Blood cholesterol and uric acid of healthy medical students under stress of an examination. A.M.A. Arch. Int. Med., 1959, 103, 708-711.

Geber, W. F., Anderson, T. A., \& Van Dyne, B. Influence of ethanol on the response of the albino rat to audio-visual and swim stress. Exp. Med. Surg., 1966, 24, 25-35.

Henry, R. J. Clinical chemistry. New York: Harper \& Row, Publ. Inc., 1964.

Lindquist, E. F. T. Design and analysis of experiments. Boston: Houghton Mifflin Co., 1953.

Naumov, V. A. Activity of cholinesterase in the central nervous system and blood in experimental traumatic shock. Materialy Nauchn. Konf. Ckelyob. Med. Inst., 1964, 111-112.

Pearl, W., Balazs, T., \& Buyske, D. A. Effect of stress on serum transaminase activity in the rat. Life Sci., 1966, 5, 67-74.

Petery, J. J. Ultramicroanalysis of selected blood components of normal macaca mulatta. Techn. Manuscr. 220, US Army Biological Lab., Fort Detrick, 1965, 1-5.

Sarai, K. Relation of the blood cholesterol level in emotional stress to the character pattern. Yonaga Acta Med., 1966, 10, 34-37.

Selye, H. Stress. Montreal: Acta, 1950.

Siegel, S. Nonparametric statistics. New York: McGraw-Hill Book Co., 1956.

Wegman, H. M., Bruener, H., Klein, K. E., \& Voigt, E. D. Enzymic and hormonal responses to exercise, lowered pressure, and acceleration in human plasma and their correlation to individual tolerances. Fed. Proc.. 1966, 25, 1405-1408.

\section{Notes}

1. This research was supported by AF Contract 29(600)-5135 between the Aeromedical Research Laboratory, Holloman AFB, New Mexico and Florida Presbyterian College.

2. A more detailed report is available from the authors upon request. 